\title{
PREVALENCE OF HYPODONTIA IN ORTHODONTIC PATIENTS AT NOBEL MEDICAL COLLEGE, BIRATNAGAR
}

\author{
Anand Acharya ${ }^{1 *}$, Nidhi Giri, Raj Kumar Jha ${ }^{2}$, Jitendra Sing ${ }^{3}$
}

\section{Affiliation}

1. Assistant Professor, Department of Orthodontics, Nobel Medical College and Teaching Hospital, Nepal

2. Lecturer, Department of Community Dentistry, Nobel Medical College and Teaching Hospital, NepaL

3.. Associate Professor, Department of Orthodontics, Nobel Medical College and Teaching Hospital, Nepal

\section{ARTICLE INFO}

Received : 26 September, 2021

Accepted : 12 January, 2022

Published : 21 February, 2022

(C) Authors retain copyright and grant the journal right of first publication with the work simultaneously licensed under Creative Commons Attribution License CC - BY 4.0 that allows others to share the work with an acknowledgment of the work's authorship and initial publication in this journal.

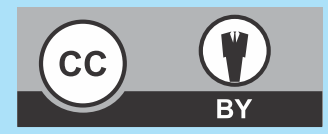

\section{ORA 281}

DOI: https://doi.org/10.3126/bjhs.v6i3.43206

* Corresponding Author

Dr. Anand Acharya

Assistant Professor

Départment of Orthodontics

Nobel Medical College Teaching Hospital, Nepal

Email: .dranandacharya@gmail.com

ORCID: https://orcid.org/0000-0001-9402-4596

\section{Citation}

Prevalence of Hypodontia in Orthodonic patients at Nobel Medical College, Biratnagar. Anand Acharya, Nidhi Giri, Raj Kumar Jha, Jitendra Singh BJHS 2021;6(3)16.1626-1630.

\section{ABSTRACT}

\section{Introduction}

Hypodontia or tooth agenesis is the most common developmental anomaly in craniofacial region. The multitude of problems in patients with hypodontia includes aesthetic, periodontal damage, malocclusion, inarticulate speech and alveolar bone deficiency. This commonly encountered condition in orthodontic department has variable site of occurrence, sometimes associated with syndromes.

\section{Objective}

To know the patterns and types of hypodontia in orthodontic patients attending orthodontic department at Nobel Medical College, Biratnagar.

\section{Methodology}

Cross sectional study of 260 orthodontic patients' pretreatment records i.e., casts, orthopantomogram, lateral cephalometric radiographs and photographs were taken as study materials. Descriptive statistics was used to analyze the data and chi square test was used to find the level of significance among genders.

\section{Result}

Congenital absence of one or more teeth was observed in 28 out of 260 patients, with a frequency of $10.8 \%$. Among the hypodontia patients, 11 (4.23\%) were males and 17 (6.54\%) were females. Of all 69 missing teeth, the most (68\%) was observed in class I group, and the least amount belonged to class III group (10\%).

\section{Conclusions}

The higher prevalence of hypodontia in Orthodontic patients in this region warrants careful inspection and investigation before embarking on the diagnosis and treatment planning.

\section{KEY WORD}

Prevalence, hypodontia, orthodontic patients, malocclusion 


\section{INTRODUCTION}

Hypodontia is the absence of one to six teeth excluding third molars. ${ }^{1,2}$ Hypodontia or tooth agenesis is the most common developmental anomaly in craniofacial region. ${ }^{3}$ Absence of more than six teeth excluding third molars is known as oligodontia. ${ }^{4,5}$ The complete failure of dentition to develop is called anodontia. ${ }^{6}$ Any tooth can be missing congenitally but there is a tendency for certain teeth to be missing more frequently than others. Graber has reported that overall frequency of missing teeth except third molars to be ranging from $1.6 \%$ to $9.6 \%$ in various series of studies in different countries. ${ }^{7}$ Hypodontia may be associated with a recognized genetic syndrome or can occur as a nonsyndromic isolated trait. ${ }^{8-11}$ In some instances familial tendency of congenitally missing single tooth has also been reported, although etiology has been unknown.

Hypodontia not only induces psychosocial problem but also imparts economical burden to the patients. The treatment of hypodontia needs multidisciplinary approach.

The multitude of problems in patients with hypodontia includes aesthetic, periodontal damage, malocclusion, inarticulate speech and alveolar bone deficiency. Individuals with hypodontia has deep overbites and spacing, reducing the size of occlusal table leading to over eruption of opposing tooth, non working interferences and poor gingival contours. Early detection of dental anomalies is vital to provide comprehensive treatment and prevent malocclusions. Study by Laing $\mathrm{E}$ et al shows chewing problems in patients with hypodontia who had deciduous teeth associated with missing permanent teeth exfoliated. ${ }^{12}$

Some studies also concluded anterior hypodontia has a significant effect on skeletal relationships. ${ }^{13}$ Hypodontia in anterior region can accompany retrognathic maxillae, prognathic mandibles and smaller lengths of posterior cranial base. ${ }^{14}$ It is not conclusive whether it tends to occur more in the maxilla or mandible and also in the anterior versus posterior segments. ${ }^{15}$ Higher prevalence of advanced hypodontia (congenital missing more than 4 teeth except third molars) and mandibular lateral incisor agenesis were found in Japanese population. ${ }^{16}$

One of the research conducted in Kathmandu, Nepal showed that hypodontia was present in 7.48 percent of orthodontic patients where as maxillary lateral incisor was found to be the most common congenital missing and microdontic tooth. ${ }^{17,18}$ No such researches have been conducted so far in this region. The aim of our study was to know the patterns and types of hypodontia in orthodontic patients attending orthodontic department at Nobel Medical College, Biratnagar.

\section{METHODOLOGY}

Cross sectional study of 260 orthodontic patients' pretreatment records i.e., casts, orthopantomogram, lateral cephalometric radiographs and photographs were taken as study materials as per convenient sampling method. This proposed study was approved by the ethical committee of Nobel Medical College and the study duration was from March 2021 to August 2021 at department of Orthodontics, Nobel Medical College. ANB angle was used to segregate malocclusion types. ANB angle between 2 and 4 degrees were categorized as class I occlusion/ malocclusion. Accordingly, higher and lower ANB angles were categorized as class II and class III malocclusions, respectively. Wits appraisal measurement was used in doubtful ANB angle cases. Wit's appraisal of 0 to -1 were classified as class I, those with positive Wit's measurements were classified as class II and negative Wit's measurements more than -1 as class III.

Statistical Analysis: The data was analyzed by using the Statistical package for Social Sciences version 23.0 software (SPSS IncChicago,IL,USA). Descriptive statistics was used to summarize the data and chi square test was used to find the level of significance among genders.

Exclusion criteria were patients with previous history of orthodontic treatment, craniofacial syndromes such as clefts, history of teeth trauma, previous extractions due to caries or periodontal disease, incomplete patient records. Third molar was not considered throughout the study. All the permanent teeth except third molars calcification had been completed by 9 years and cases with missing teeth due to extraction were not included in the study on account of confounding the result. Early detection before that age may be unreliable and confound the result. ${ }^{1}$ Calcification of premolars may be delayed due to various factors. ${ }^{4}$

\section{RESULTS}

The distribution of tooth agenesis according to gender in different malocclusion groups is shown in Table 1.From the total cases examined, 77(29.6\%) were males and 183 (70.4\%) were females. Class I malocclusion was found in 171 patients $(65.8 \%)$ which is the most common malocclusion among the study patients. [Table 1]. Congenital absence of one or more teeth was observed in 28 out of 260 patients, with a frequency of $10.8 \%$. Also, among the 28 patients with hypodontia, 20 (11.7\%) patients belonged to class I, 7(8.6\%) belonged to class II, and $1(12.5 \%)$ belonged to class III malocclusion [Figure 1].



Figure 1: Distribution of hypodontia according to malocclusion types 
Also, from all of the patients with missing teeth, 11 (4.23\%) were males and 17 (6.54\%) were females [Table 2]. Chi square test was done to know distribution of hypodontia among genders and different classes of malocclusion and it showed that most of the hypodontia was found in class I malocclusion (71.4\%) and females were affected more though not significant $(P=0.235)$. On the other hand lowest number of class III malocclusion patients (3.6\%) had hypodontia [Table 3].

Out of 28 hypodontia patients, $15(53.6 \%)$ had missing teeth in the upper arch in all types of malocclusion where as $21(75 \%)$ had bilateral missing teeth. This higher frequency of hypodontia in the upper arch was observed in all types of malocclusions [Table 4].

\begin{tabular}{|c|c|c|c|c|}
\hline & \multicolumn{2}{|c|}{ Gender } & \multirow[t]{2}{*}{ Total } & \multirow[t]{2}{*}{ P-value } \\
\hline & Male & Female & & \\
\hline Total sample & 77 (29.6\%) & $183(70.4 \%)$ & $260(100 \%)$ & NA \\
\hline Hypodontia & $11(4.23 \%)$ & 17 (6.54\%) & $28(10.8 \%)$ & $0.235^{*}$ \\
\hline
\end{tabular}

Table 3: Distribution of gender across different classes of malocclusion among participants with hypodontia.

\begin{tabular}{|c|c|c|c|c|}
\hline \multicolumn{2}{|c|}{} & \multicolumn{3}{c|}{ Malocclusion } \\
\cline { 3 - 5 } \multicolumn{2}{|c|}{} & Class I & Class II & Class III \\
\hline \multirow{2}{*}{ Gender } & Male & 7 & 3 & 1 \\
\cline { 2 - 5 } & Female & 13 & 4 & 0 \\
\hline \multicolumn{2}{|c|}{ Total } & $\mathbf{2 0 ( 7 1 . 4 \% )}$ & $\mathbf{7 ( 2 5 \% )}$ & $\mathbf{1 ( 3 . 6 \% )}$ \\
\hline
\end{tabular}

Table 4: Prevalence of missing teeth in different types of malocclusions with respect to the affected jaw and side.

\begin{tabular}{|c|c|c|c|c|c|c|}
\hline & Upper arch & $\begin{array}{c}\text { Lower } \\
\text { arch }\end{array}$ & $\begin{array}{c}\text { Both } \\
\text { arch }\end{array}$ & Left & Right & Bilateral \\
\hline Class I & 9 & 5 & 6 & 5 & 1 & 14 \\
\hline Class II & 4 & 2 & 1 & 0 & 1 & 6 \\
\hline Class III & 2 & 0 & 1 & 1 & 1 & 1 \\
\hline Total & $15(53.6 \%)$ & $7(25 \%)$ & $8(28.6 \%)$ & $6(21.4 \%)$ & $3(10.7 \%)$ & $21(75 \%)$ \\
\hline
\end{tabular}

There were a total of 69 missing teeth in our examined patients. Of all 69 missing teeth, the most (68\%) was observed in class I group, and the least amount belonged to class III group (10\%). However, there was no statistical significant difference between different malocclusions in the number of missing teeth. (Chi-square test, $P>0.05$ ). The most and the least affected teeth were upper lateral incisor (30.43\%) and lower first premolar (1.45\%), respectively. Thus, the most prevalent missing tooth types were found more in class I patients and females had more number of absent teeth (54\%).[Table 5]
Table 5:Prevalence of various tooth type agenesis in different malocclusions and genders ( $n=$ missing teeth).

\begin{tabular}{|c|c|c|c|c|c|c|}
\hline \multirow[t]{2}{*}{ Missing teeth } & \multicolumn{3}{|c|}{ Malocclusion } & \multicolumn{2}{|c|}{ Gender } & \multirow[t]{2}{*}{ Total } \\
\hline & Class I & Class II & Class III & Male & Female & \\
\hline $\begin{array}{l}\text { Lower second } \\
\text { premolar }\end{array}$ & $8(17.02 \%)$ & $2(13.33 \%)$ & 0 & $5(15.63 \%)$ & $5(13.51 \%)$ & $10(14.49 \%)$ \\
\hline $\begin{array}{l}\text { Lower first } \\
\text { premolar }\end{array}$ & $1(2.13 \%)$ & 0 & 0 & $1(3.13 \%)$ & 0 & $1(1.45 \%)$ \\
\hline Lower canines & $1(2.13 \%)$ & $3(20 \%)$ & 0 & $2(6.25 \%)$ & $2(5.41 \%)$ & $4(5.80 \%)$ \\
\hline $\begin{array}{l}\text { Lower central } \\
\text { incisor }\end{array}$ & $7(14.89 \%)$ & 0 & $1(14.29 \%)$ & $6(18.75 \%)$ & 2 (5.41\%) & $8(11.59 \%)$ \\
\hline $\begin{array}{l}\text { Lower lateral } \\
\text { incisor }\end{array}$ & $2(4.26 \%)$ & 0 & 0 & $2(6.25 \%)$ & 0 & $2(2.90 \%)$ \\
\hline $\begin{array}{l}\text { Upper second } \\
\text { premolar }\end{array}$ & $6(12.77 \%)$ & 0 & 0 & $3(9.38 \%)$ & $3(8.11 \%)$ & $6(8.70 \%)$ \\
\hline $\begin{array}{l}\text { Upper first } \\
\text { premolar }\end{array}$ & $3(6.38 \%)$ & 0 & 0 & 1 (3.13\%) & $2(5.41 \%)$ & $3(4.35 \%)$ \\
\hline Upper canine & $7(14.89 \%)$ & $4(26.67 \%)$ & $1(14.29 \%)$ & $4(12.5 \%)$ & $8(21.62 \%)$ & $12(17.39 \%)$ \\
\hline $\begin{array}{l}\text { Upper central } \\
\text { incisor }\end{array}$ & $1(2.13 \%)$ & $1(6.67 \%)$ & 0 & 0 & $2(5.41 \%)$ & $2(2.90 \%)$ \\
\hline $\begin{array}{l}\text { Upper lateral } \\
\text { incisor }\end{array}$ & $11(23.40)$ & $5(13.33 \%)$ & $5(71.43)$ & $8(25 \%)$ & $13(35.14)$ & $21(30.43 \%)$ \\
\hline Total & $47(68 \%)$ & $15(22 \%)$ & $7(10 \%)$ & $32(46 \%)$ & $37(54 \%)$ & $69(100 \%)$ \\
\hline
\end{tabular}

\section{DISCUSSION}

Out of 260 patients, $10.8 \%$ had hypodontia. Age range of our patients were 9 to 32 years. Female orthodontic patients show higher preponderance as compared to males in our study owing to more esthetic concern of females consistent with many other researches. Hypodontia was found in $10.8 \%$ of our study patients which was higher than study by Gupta et al $(7.48 \%)$ in the orthodontic patients in Kathmandu. ${ }^{17}$ Different ethnicity or geographic difference in the study could also affect the result. HK Sony et al in a study conducted in Varodara, Gujrat India reported hypodontia present in $11.01 \%$ of cases which is comparable to our study. ${ }^{19}$ The highest prevalence was found to be in German population (12.6\%)and least in the Malaysian (2.8\%). ${ }^{20,21}$

Overall hypodontia was found to be more common in females(6.54\%) as compared to males(4.23\%) but not statistically significant. Similarly, out of 28 patients with missing teeth $17(61 \%)$ were females and $11(39 \%)$ were males, comparable to previous study. ${ }^{17,22-26}$

The missing teeth were more often absent in the maxillary arch consistent with the previous research. ${ }^{22,27-29}$ Upper lateral incisors was the most commonly missing where as lower first premolar was least commonly missing. $\mathrm{H} \mathrm{K}$ Sony et al, Chung et al and Hassan et al reported missing teeth was more frequently found in mandibular arch. ${ }^{19,30,31}$ The prevalence of congenitally missing teeth was almost equal in both the jaws as reported by Polder et al. ${ }^{32}$ Bilateral missing lateral incisor was more frequently noted. Polastri in the study on Italian population had similar findings whereas Graccoet al., Laganàet al., and Sato et al. found that the most affected tooth was the mandibular second premolars followed by maxillary lateral incisor. ${ }^{33-36}$ The reason behind this difference could be attributed to difference in sample size, type of population, genetic factors and method of data collection in the different study groups.

Most of our hypodontia patients belonged to class I malocclusion group (68\%) which is similar to the findings of Celikoglu et al. ${ }^{37}$ The least number of patients belonged to class III group, statistical significance was not observed though. About $65.8 \%$ of our patients had class I malocclusion followed by $31.2 \%$ class II and least $3.1 \%$ class III which was 
comparable to previous research conducted in the orthodontic department at Nobel Medical College, Biratnagar. $^{38}$

\section{CONCLUSION}

The higher prevalence of hypodontia in Orthodontic patients in this region warrants careful inspection and investigation before embarking on the diagnosis and treatment planning. It seems hypodontia appears more in the maxilla than in the mandible and it can accompany various complications.

\section{RECOMMENDATION}

From our study we have found that hypodontia is common in orthodontic patients. Proper investigations like case history, orthopantamogram and study models are mandatory. Further research is recommended increasing the sample size and segregating the ethnicity to find ethnic preponderance of hypodontia in this region.

\section{LIMITATIONS OF STUDY}

Our study had samples collected from a single center only which could limit actual reflection of hypodontia in the orthodontic patients in this region. Furthermore sample size was small for the prevalence study.

\section{ACKNOWLEDGEMENT}

I would like to thank Dr Tarakant Bhagat, Department of Community Dentistry, BPKIHS for statistical analysis and interpretation of data and IRC Nobel Medical College for ethical clearance.

\section{CONFLICTS OF INTERESTS}

None

\section{FINANCIAL DISCLOSURE \\ None}

14. Kumar SK, Lakshmi AV, Namita S, Elumalai M. Craniofacial morphologic variations and its association with hypodontia pattern (Anterior) in South Indian female population. BiosciBiotechnol Res Asia 2013;10:325-8.http://dx.doi.org/10.13005/bbra/1129

15. Rakhshan V. Congenitally missing teeth (hypodontia): A review of the literature concerning the etiology, prevalence, risk factors, patterns and treatment. Dental Research Journal 2015 vol 12 Issue 1 [PMID: 25709668]

16. Toshiya Endo, Rieko Ozoe, Mifumi Kubota, Mahito Akiyama, and ShohachiShimooka.A survey of hypodontia in Japanese orthodontic patients. Am J OrthodDentofacialOrthop 2006;129:29-35. DOI: 10.1016/j.ajodo.2004.09.024.

17. Gupta S P, Rauniyar S. Prevalence and distribution of dental agenesis among Orthodontic patients of Kathmandu. Arch Med Health Sci 2019;7:172-6.DOI: 10.4103/amhs.amhs_103_19

18. Gupta S P, Rauniyar S. Prevalence and Distribution of Dental Anomalies among Orthodontic Patients of Kathmandu, NepalOrthod J Nepal Vol 9 No 2; 2019:23-28https://doi.org/10.3126/ojn.v9i2.28407

19.Sony H K,Manjiri J, Desai H, Vasavada M. An orthopantomographic study of prevalence of hypodontia and hyperdontia in permanent dentition in Vadodara, Gujarat.Indian J Dent Research Vol 29 No 4; 2018:529-33 DOI: 10.4103/ijdr.IJDR_215_16

20. Behr M, Proff P, Leitzmann M, Pretzel M, Handel G, Schmalz G, et al. Survey of congenitally missing teeth in orthodontic patients in EasternBavaria. Eur J Orthod 2011;33:32-6DOI: 10.1093/ejo/cjq021

21. Nik-Hussein NN. Hypodontia in the permanent dentition: A study of its prevalence in Malaysian children. AustOrthod J 1989;11:93-5.[PMID 2639661]

22. ZohrehHedayati, YunesNazariDashlibrunThe prevalence and distribution pattern of hypodontia among orthodontic patients in Southern Iran. European Journal of Dentistry, Vol 7 / Supplement 1 / Sept 2013[PMID 24966733]

23. Goya HA, Tanaka S, Maeda T, Akimoto Y. An orthopantomographic study of hypodontia in permanent teeth of Japanese pediatric patients. J Oral Sci; 2008 June 50(2):143-50. DOI: 10.2334/josnusd.50.143.

24. Endo T, Ozeo R, Kubota M, Akiyama M, Shimooka S. A survey of hypodontia in Japanese orthodontic patients. Am J Orthod DentofacialOrthop 2006;129:29-35. DOI: 10.1016/j.ajodo. 2004.09.024

13. Acharya PN, Jones SP, Moles D, Gill D, Hunt NP. A cephalometric study to investigate the skeletal relationships in patients with increasing severity of hypodontia. Angle Orthod. 2010;80:511-8. [PubMed: 20482356] 
25. Vahid-Dastjerdi E, Borzabadi-Farahani A, Mahdian M, Amini N. Non-syndromichypodontia in an Iranian orthodontic population. J Oral Sci 2010:52:455-61. [PMID 20881340]

26. Kapdan A, Kustarci A, Buldur B, Arslan D, Kapdan A. Dental anomalies in the primary dentition of Turkish children. Eur J Dent 2012;6:178-83. [PMID 22509121]

27. Medina AC. Radiographic study of prevalence and distribution of hypodontia in a pediatric orthodontic population in Venezuela. Pediatr Dent 2012;34(2):113-6. [PMID 22583882]

28. Vahid-Dastjerdi E, Borzabadi-Farahani A, Mahdian M, Amini N. Non-syndromichypodontia in an Iranian orthodontic population. J Oral Sci 2010:52:455-61.DOI: 10.2334/josnusd.52.455

29. Sisman Y, Uysal T, Gelgor IE. Hypodontia. Does the prevalence and distribution pattern differ in orthodontic patients? Eur J Dent. 2007;1:167-73. [PMID 19212561]

30. Chung CJ, Han JH, Kim KH. The pattern and prevalence of hypodontia in Koreans. Oral Dis 2008;14:620-5. [PMID 18248591]

31. Hassan DA, Abuaffan AH, Hashim HA. Prevalence of hypodontia in a sample of Sudanese orthodontic patients. J OrthodSci 2014;3:63-7. [PMID 25143929]

32.Polder BJ, Van't Hof MA, Van der Linden FP, Kuijpers-Jagtman AM. A meta-analysis of the prevalence of dental agenesis of permanent teeth. Community Dent Oral Epidemiol 2004;32:217-26.[PMID: 15151692]
33. Polastri F, Cerato E, Gallesio C. The clinico-radiological assessment of dental anomalies with real and apparent numerical defects. Minerva Stomatol 1991;40:415-23.[PMID: 1944057]

34. Gracco AL, Zanatta S, ForinValvecchi F, Bignotti D, Perri A, Baciliero F. Prevalence of dental agenesis in a sample of Italian orthodontic patients: An epidemiological study. ProgOrthod 2017;18:33.[PMID: 29034420]

35. Laganà G, Venza N, Borzabadi-Farahani A, Fabi F, Danesi C, CozzaP.Dental anomalies: Prevalence and associations between them in a large sample of non-orthodontic subjects, a cross-sectional study. BMC Oral Health 2017;17:62.[PMID: 28284207]

36. Sato A, Arai K. Estimation of tooth agenesis risks between tooth types in orthodontic patients with non-syndromicoligodontia. Orthod Waves 2019;4:1-7.https://doi.org/10.1016/j.odw.2019.04.001

37. Celikoglu M, Kazanci F, Miloglu O, Oztek O, Kamak H, Ceylan I. Frequency and characteristics of tooth agenesis among an orthodontic patient population. Med Oral Patol Oral Cir Bucal 2010;15:e797-801.DOI: 10.4317/medoral.15.e797.

38. Acharya A, Bhattarai B, George D, Bhagat T. Pattern of Malocclusion in Orthodontic Patients in South-Eastern Region of Nepal.Orthod J Nepal Vol 7 No 1; 2017:7-9 https://doi.org/10.3126/ojn.v7i1.18893 